اثر جيرههاى غذايى حاوى سطوح مختلف كنجاله سويا و مولتى آنزيم كمين بر عملكرد رشد، تركيبلاشه و باكترىهاى

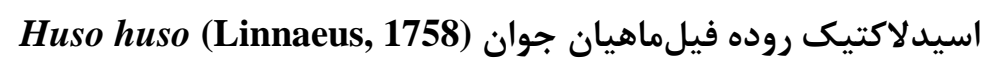

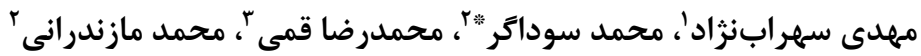

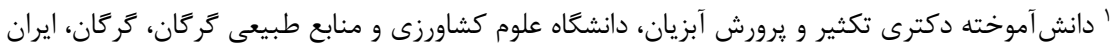

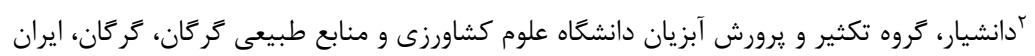

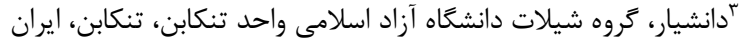

\begin{abstract}
جكيده در مطالعه حاضر، تأثير جايكزينى يودر ماهى با كنجاله سويا بر عملكرد رشد، تركيب لاشه و باكترىهاى اسيد

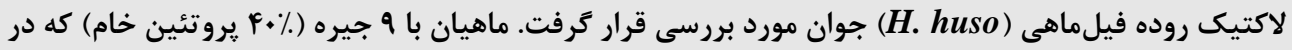

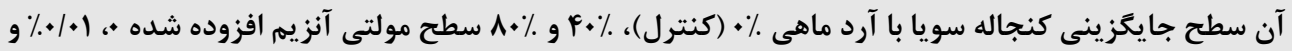

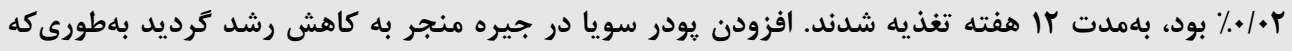

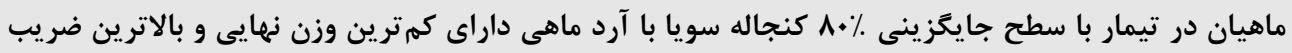

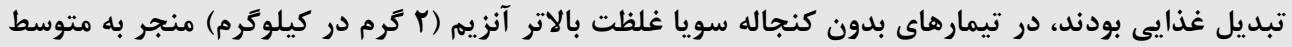

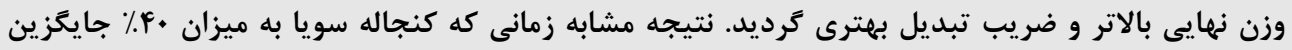

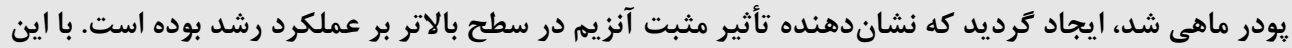

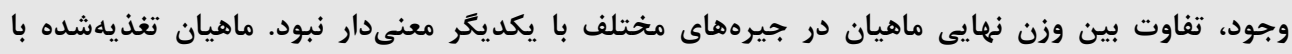

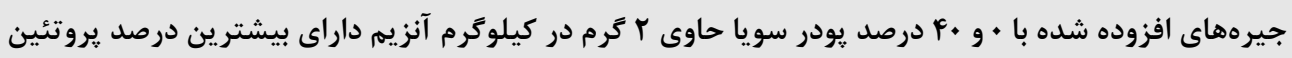

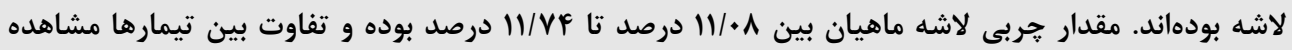

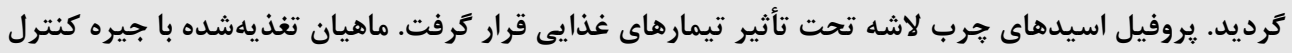

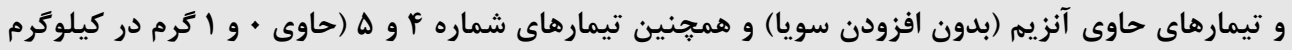

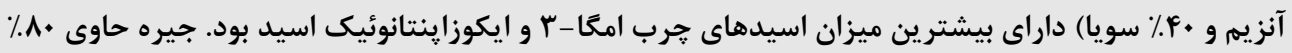

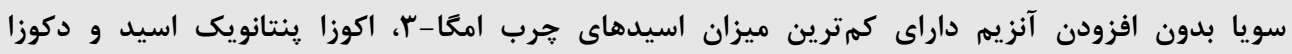

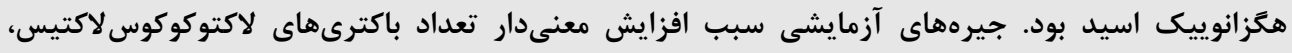

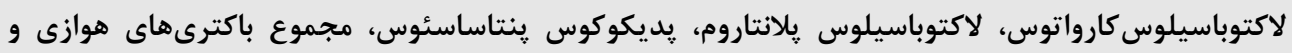

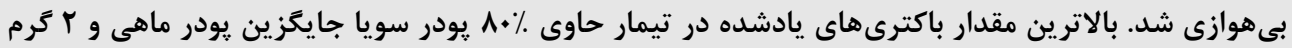

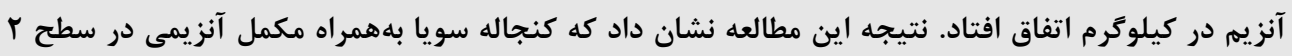

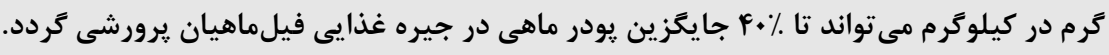
وازمهاي كليدى:

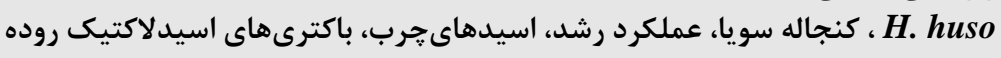

آبزى يرورى بايدار و اقتصادى بوده و موضوع تحقيقات براى حداقل r

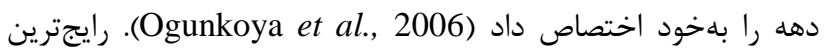

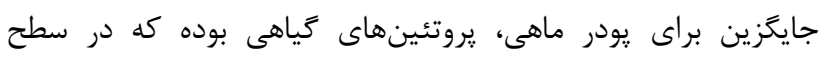

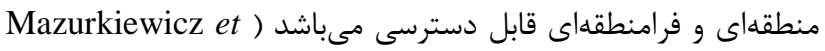

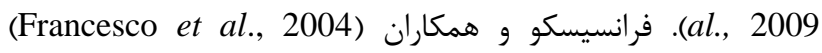

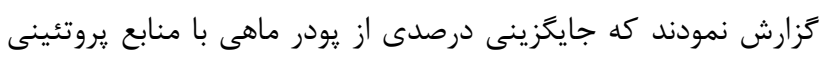

نوع مقاله: يزووهشى اصيل

تاريخجه مقاله:

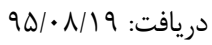

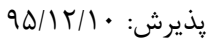

نويسنده مسئول مكاتبه: محمد سوداگر، دانشيار، كروه تكثير و يرورش آبزيان

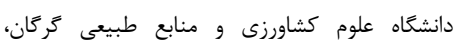

كر كان، ايران. ايميل:yahoo.com
امروزه اولويت فعاليتهاى آبزى يرورى خصوصاً در گَونهاى بارزش

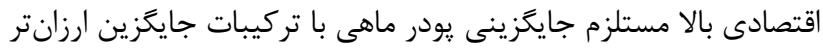

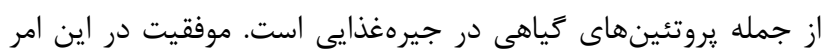
Gatlin et al., 2007; ) موجب يايدارى صنعت آبزى يرورى خواهي Castillo and Gatlin, 2015

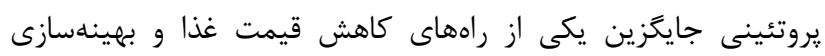


آبزيان از جمله استرلت (Ustaoglu and Rennert, 2002)، قزل آلاى (U)

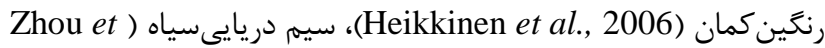
Lin and Li, ) (al., 2011

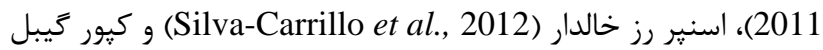
نيز كزارش گرديده است.

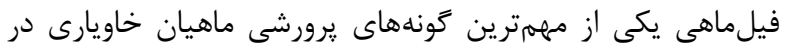

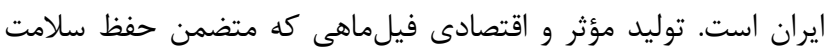
نيز باشد مستلزم تأمين موادمغذى ضرورى در در كنار توجه بـ به كاهش

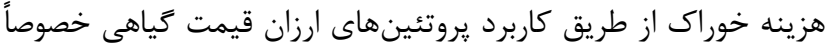

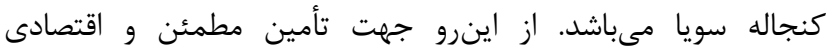
فيلماهى، فرمولاسيون جيرههاى موجود با استفاده از كنجاله سويا و مكملهاى آنزيمى جهت برماهي

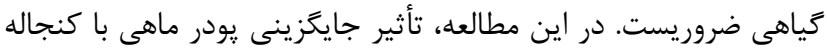

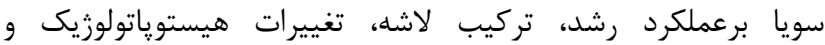

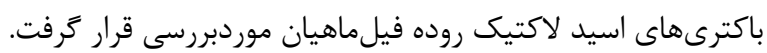

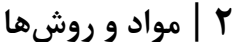

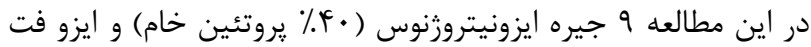

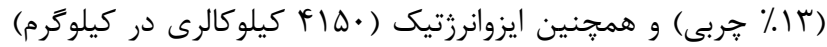

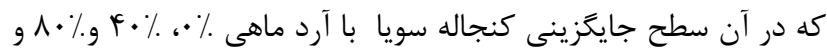

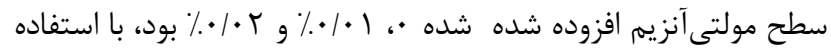
از نرمافزار UFFDA تنظيم كرديد (جدول ()). بعد از تركيب مواد اوليه يرمقدار با يكديگر مكمل معدنى و ويتامينه (سيانس)، متيونين

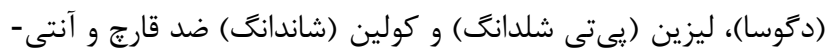
اكسيدان (نوترى ادد)، بايندر (زرين بايندر)، دى كلسيم فسفات إنسات (يويا

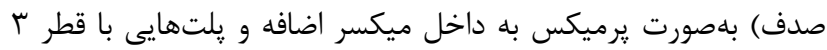

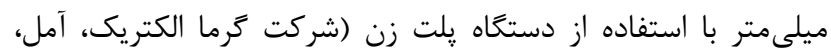

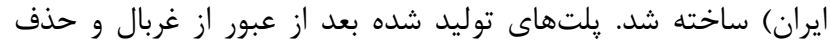

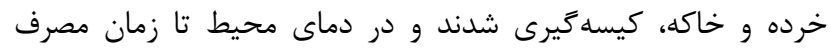
نكهدارى شدند (Sohrabnezhad et al., 2017).

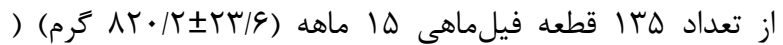

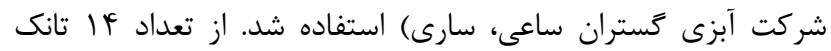

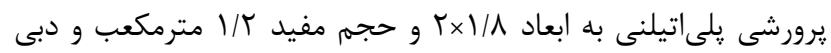

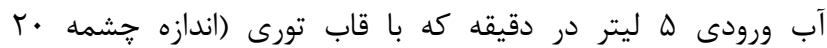

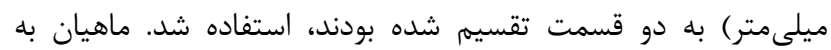

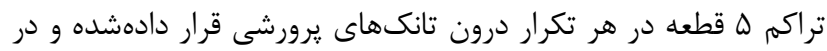

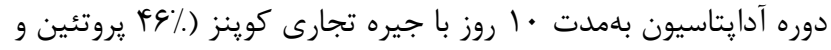

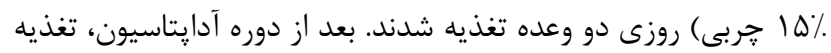

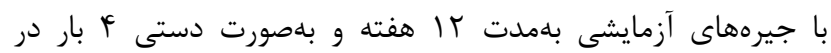

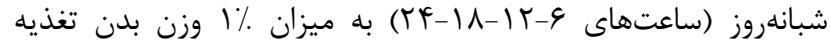

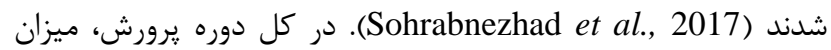

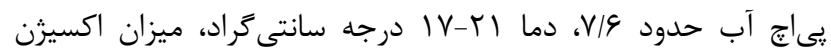

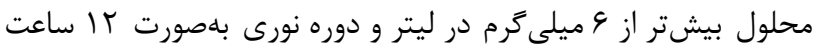

كياهى مىتواند به لحاظ تغذيهاى مورد قبول ماهى واقع شودو از اينرو

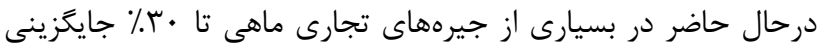

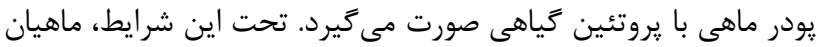

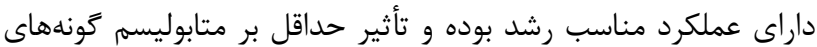
ماهى داشته است. در بين مواد كياهى، سويا (كلايسين ماكس، لينه اوس) داراى

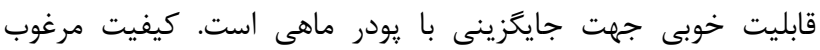

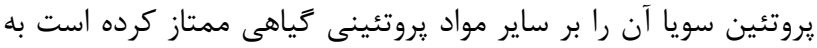

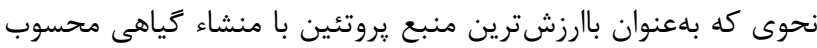

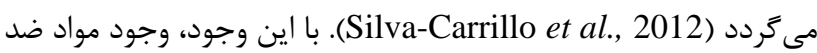

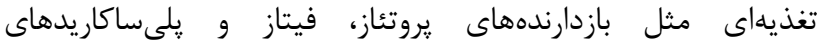
غيرنشاستهاى در : بروتئينهاى خياهى (Francis et al., 2001) و

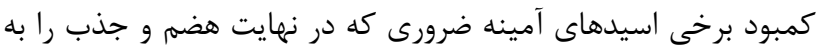

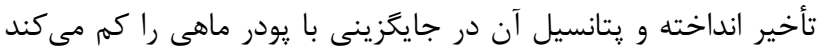

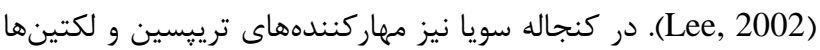

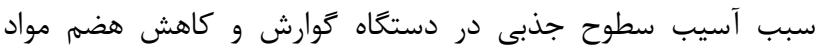

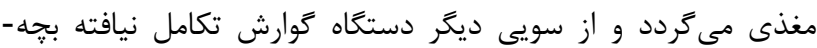

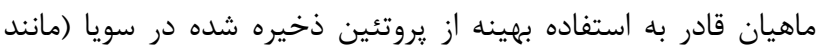
كليسينين و بتاكنغليسينين) نيست.

نتيجه برخى مطالعات نشان داد كه افزودن آنزيم به شكل مكمل نئاكل

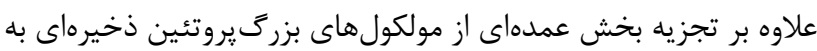

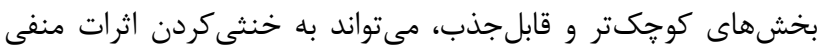

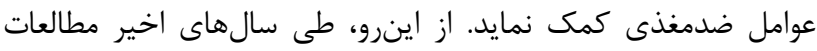

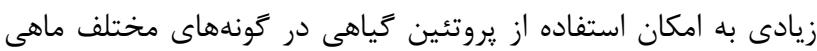

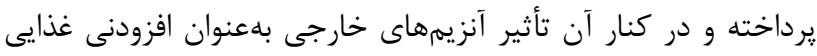

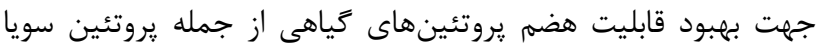

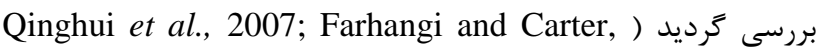
Ghomi et ( 2007; Yildirim and Turan, 2010 اثر مولتى آنزيم كمين را جيره فيلماهى مورد بررسى قرار (al., 2012 دادند. بهترين ضريب رشد ويزه و كمترين ضريب تبر تبدي

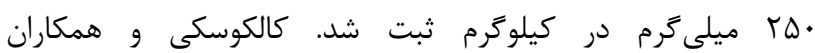
(Kolkovski et al., 1993)

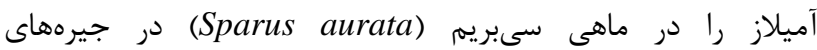

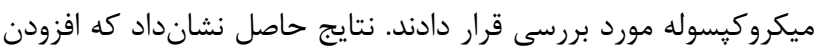

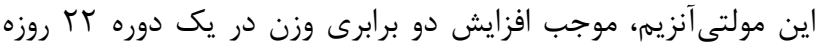
شد كه •4. بالاتر از كروه شاهد صفر بود. يعقوبى و همكاران تأثير جايخزينى يودر ماهى با يودر سويا و

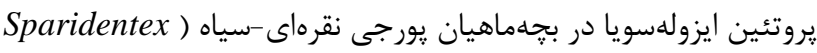

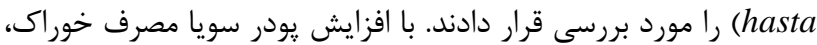

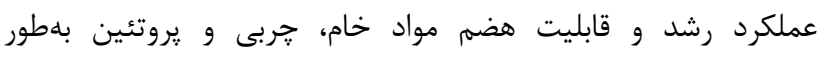

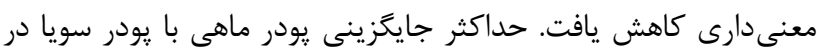

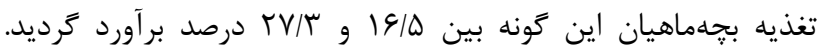
تأثير جايخزينى :ودر ماهى با بودر سويا در جيره غذايى گَونههاى ديخر 
ساعت تعيين شد (AOAC, 1990).

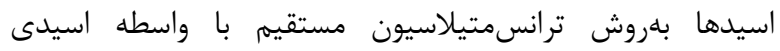
با استفاده از دستخاه (direct acid-catalyzed transmethylation) كاز كروماتوكرافى مدل Agilent 7890 با دتكتور FID و ستون TQ/·Agilent J\&W DB-225MS

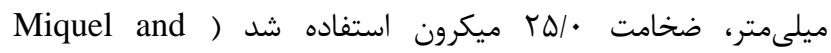

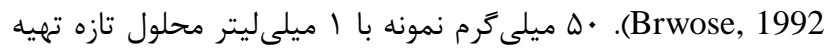

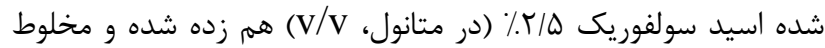

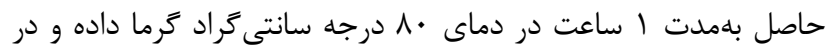

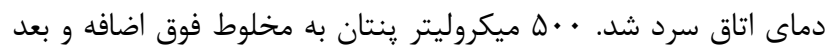

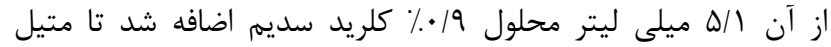

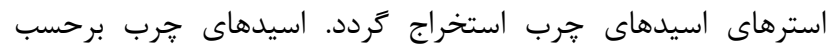

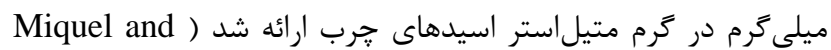

(Brwose, 1992
روشنايى و Ir ساعت تاريكى بود. در تانكهاى يرورشى ماهيان هر جهار هفته وزن مىشدند تا بيوماس ماهى در هر تانك مشخص كرد برد.

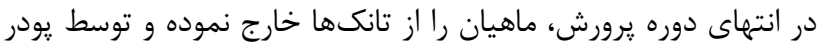
كل ميخك به مقدار ه| • ترم در ليتر (Hallajian et al., 2011)

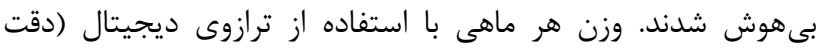
1.

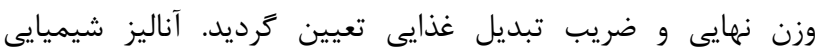
جيرههاى غذايى و كوشت ماهى به روش استاندارد (AOAC, 1990)

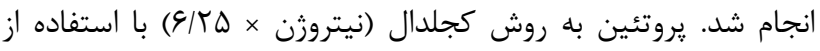

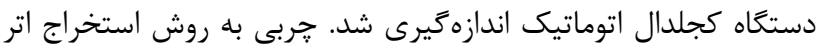

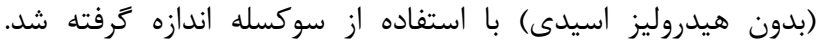

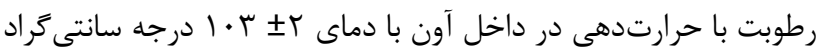

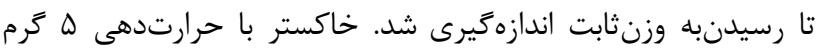

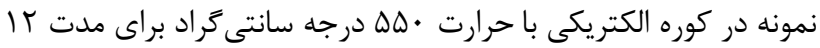

جدول ا - تركيب عناصر و آناليز شيميايى جيرههاى آزمايشى بررسى جايكزينى بودر ماهى با كنجاله سويا بر عملكرد رشد، تركيب لاشه و باكترىهاى اسيد لاكتيك

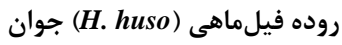

\begin{tabular}{|c|c|c|c|c|c|c|c|c|c|}
\hline \multicolumn{10}{|c|}{ جيره هاى آزمايشى } \\
\hline 9 & $\Lambda$ & $\mathrm{v}$ & 4 & $\Delta$ & r & $r$ & r & 1 & اقلام مصرفى(.) \\
\hline 1. & 1. & 1. & $r$. & $r \cdot$ & $r$. & $\Delta$. & $\Delta$. & $\Delta$. & يودر ماهى \\
\hline r. & r. & r. & r. & $r$. & $r \cdot$ & . & . & . & آرد سويا \\
\hline$r t / r$ & $T r / \cdot r$ & $r T / \cdot r$ & $|r /| 9$ & $\mid r / 19$ & $\mid r / 19$ & $r / \Delta \mid$ & $r / Q \mid$ & $r / \Delta \mid$ & كلوتن گَندم \\
\hline$r / q$ & $r / 9$ & $r / 9$ & $\mid \Delta / / \mu$ & $10 / 14$ & $10 / 14$ & rF/qT & $T F / q T$ & rF/qT & آرد كَندم \\
\hline$\Delta / \pi \Delta$ & $\Delta / \sim_{\Delta}$ & $\Delta / r \Delta$ & $r / q V$ & $r / 9 V$ & $r / 9 V$ & $F / / F$ & $F / l f$ & $F / / f$ & روغن سويا \\
\hline$\Delta / r \Delta$ & $\Delta / r \Delta$ & $\Delta / r \Delta$ & $r / 9 \mathrm{~V}$ & $r / q V$ & $F / Q V$ & $F / l F$ & $F / l f$ & $F / l f$ & روغن ماهى \\
\hline r & r & r & r & r & r & r & r & r & ملاس \\
\hline r & r & r & r & r & r & r & r & r & مكمل معدنى \\
\hline r & r & r & r & r & r & r & r & r & مكمل ويتامينه \\
\hline r & r & r & r & r & r & r & r & r & دى كلسيم فسفات \\
\hline $.1 \cdot r$ &.$/ \cdot r$ &.$/ \cdot r$ & $.1 \cdot r$ &.$/ \cdot r$ &.$/ \cdot r$ & . $/ \cdot T$ &.$/ \cdot r$ & $.1 \cdot 4$ & آنتى اكسيدان \\
\hline$\cdot / T \Delta$ & $\cdot / T \Delta$ & $\cdot / T \Delta$ & $\cdot / r \Delta$ & $\cdot / T \Delta$ & $\cdot / T \Delta$ & $\cdot / T \Delta$ & $\cdot / r \Delta$ & $\cdot / T \Delta$ & ضد قارج \\
\hline$\cdot$ & $\cdot$ & $\cdot$ & - & $\cdot$ & $\cdot$ &.$/ 91$ & .191 & .191 & فيلر \\
\hline r & r & r & r & r & r & r & r & r & بايندر \\
\hline$\cdot 10$ & $\cdot / 0$ & $\cdot 10$ & $\cdot 10$ & $\cdot / 0$ & $\cdot / \Delta$ & $\cdot 10$ & $\cdot 10$ & $\cdot 10$ & متيونين \\
\hline$\cdot 10$ & $\cdot / \Delta$ & $\cdot 10$ & $\cdot / \Delta$ & $\cdot 10$ & $\cdot / \Delta$ & $\cdot 10$ & $\cdot / \Delta$ & $\cdot 10$ & ليزين \\
\hline$\cdot 11$ & $\cdot 11$ & $\cdot 11$ & .11 & $\cdot 11$ & $\cdot 11$ & $\cdot 11$ & .11 & $\cdot 11$ & كولين كلرايد \\
\hline$\cdot / 4$ & $\cdot / 1$ & . & $\cdot \pi$ & $\cdot / 1$ & . & $\cdot / r$ & $\cdot 11$ & . & مولتى آنزيم كمين \\
\hline r. & r. & r. & r. & r. & f. & r. & f. & r. & يروتئين(/) \\
\hline ir & r & r & ir & ir & ir & $\mid r / T V$ & $\mid r / T V$ & $I r / T V$ & קربى(/) \\
\hline$r \cdot \pi q$ & $r \cdot / T_{G}$ & $r \cdot \pi q$ & 19/9r & 19/94 & 19/9 & $\mid N / \Delta$ & $1 N / \Delta$ & $1 N / \Delta$ & كربو هيدرات(.) \\
\hline fivq & fiva & fivq & fIVE & five & fIVE & fia. & Fia. & Yia. & (كيلو كالرى /كيلو \\
\hline
\end{tabular}


كرديد بهطورى كه ماهيان تيمار 9 بيشترين جربى را در لاشه داشتهاند.

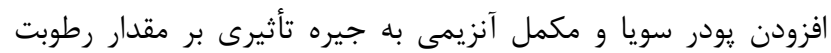

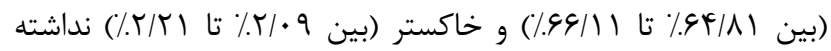

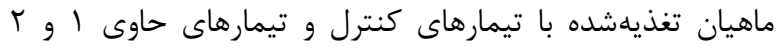

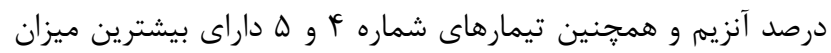

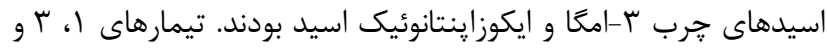

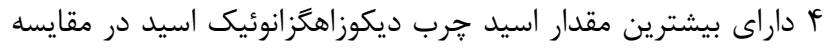

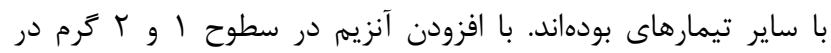

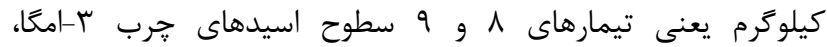

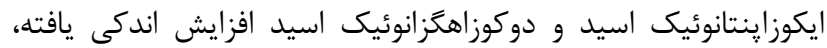

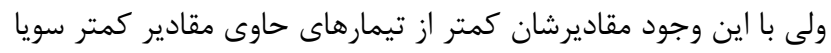

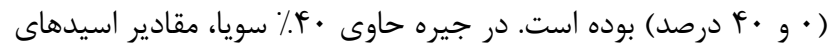

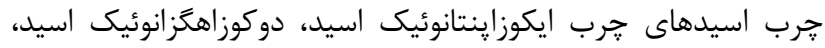

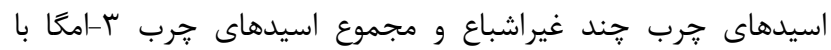

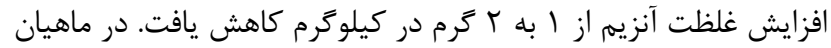

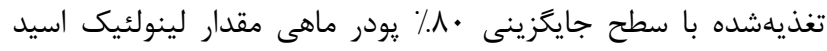

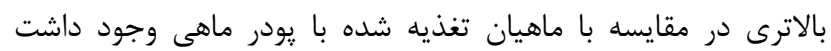

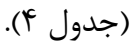

تغييرات مربوط به باكترىهاى اسيدلاكتيك روده فيلماهيان در

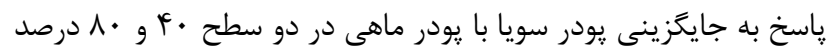

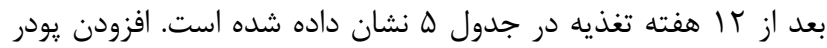

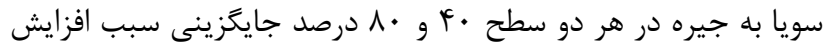

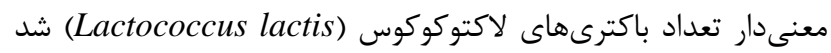
.$(p \leq \cdot / \cdot \Delta)$

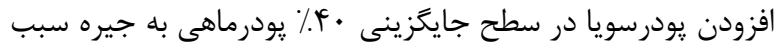
افزايش معنىدار تعداد باكترىهاى لاكتوباسيلوس ( Lactobacillus Lactococcus كرديد (ه) (curvatus lactis

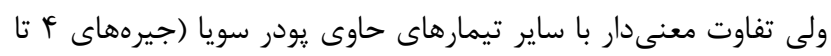

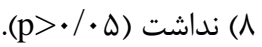

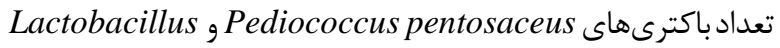

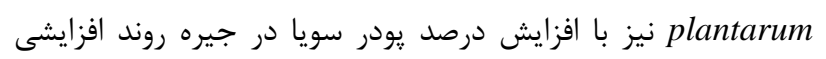

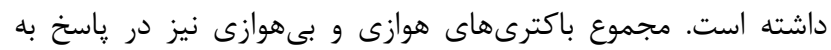

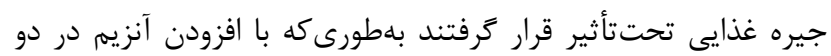

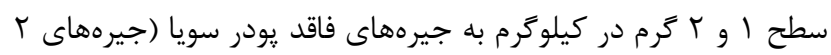

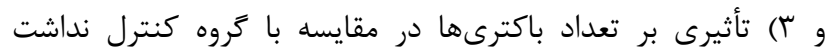

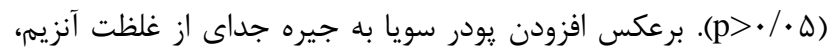
سبب افزايش اين دسته از باكترىها شد.

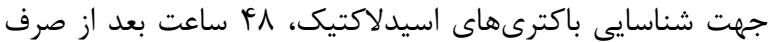

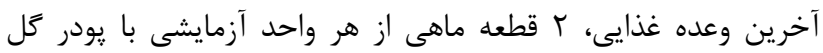

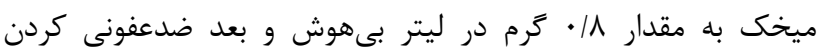

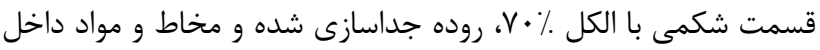

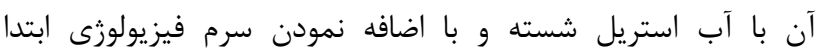

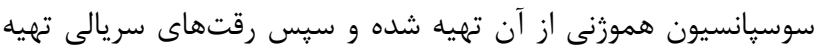

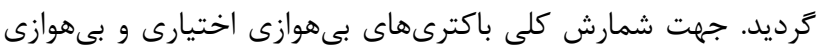

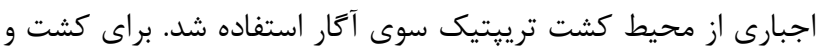

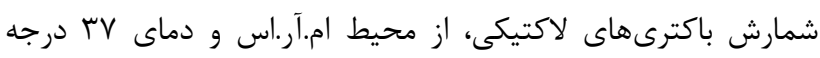

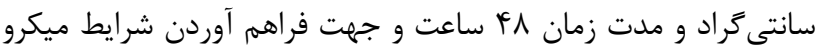

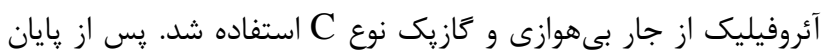

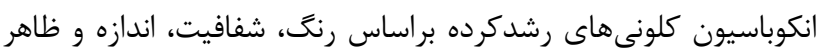

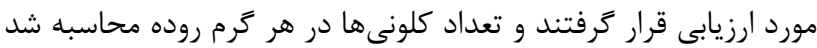

.(Esmailli et al., 2010)

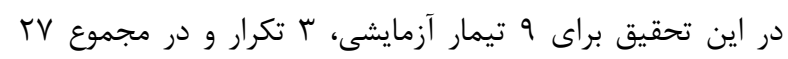

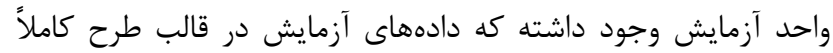

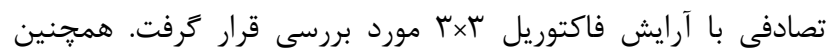

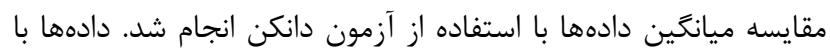

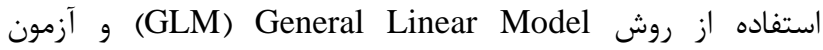

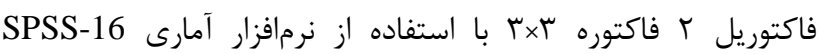

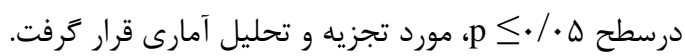

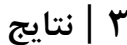

عملكرد رشد فيلماهيان تغذيهشده با جيرههاى مختلف حاوى يودر

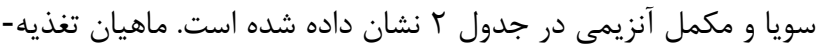

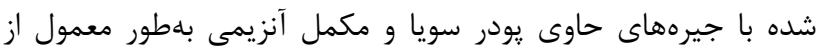

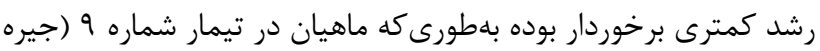

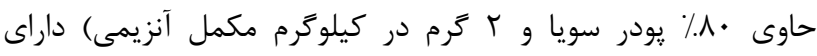

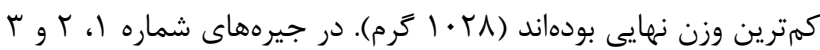

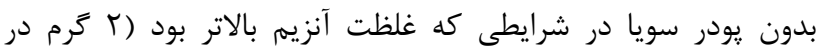

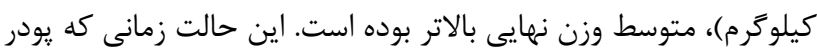

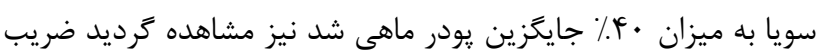

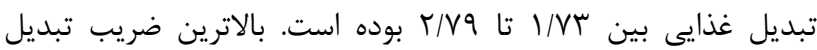

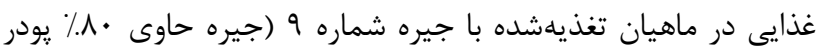

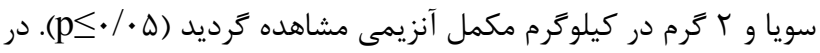

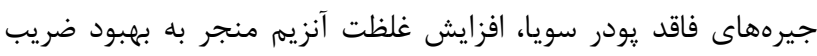

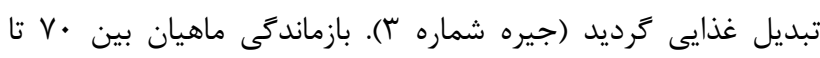

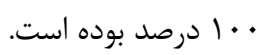

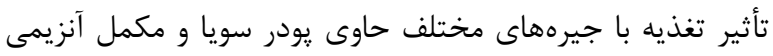
بر تركيب شيميايى لاشه در جدول ب نشان داده شده است. مادئ ماهيان

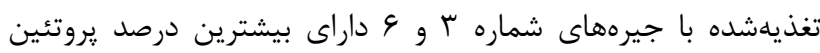

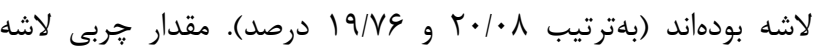

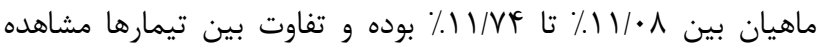


جدول r- رشد و راندمان غذايى فيلماهى (H. huso) جوان تغذيهشده با جيرههاى حاوى بودر سويا و مكمل آنزيمى به مدت rا هفته

\begin{tabular}{|c|c|c|c|c|c|c|c|c|c|}
\hline \multicolumn{9}{|c|}{ جيره هاى آزمايشى } & \\
\hline 9 & $\Lambda$ & $v$ & 4 & $\Delta$ & F & $r$ & $r$ & 1 & \\
\hline 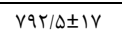 & $\Lambda r \Delta \pm r \Delta$ & vif $\pm r$ & $q \cdot r \pm r 1$ & $\Lambda \cdot f \pm 11$ & AFTEFr & $\Lambda \mid \Delta / \cdot \pm V V$ & AIrEIV & ${ }^{b} \wedge V / \cdot \pm I f$ & وزن اوليه \\
\hline$b_{1} \cdot r N / \Delta \pm r r$ & $\| r q / . \pm \Delta v^{a}$ & $|r| r \pm q q^{a b}$ & $1 \varphi \psi v \pm r \Delta v^{a}$ & $a b \mid r \lambda f \pm I V$ & ab|rrr/. \pm 111 & $a b_{1}|f| Q / 9 \pm \mid r \Lambda$ & $a b|r \cdot \cdot / \cdot \pm| r f$ & $a_{1 / \cdot \pm 1 r a}$ & وزن نهايى \\
\hline aץ/Vq & $b_{Y / Y} \mid \Psi \pm \cdot / \cdot \Lambda$ & $\mathrm{ab}_{\Gamma / T r \pm} \cdot / r$ & ${ }^{b} \backslash / \Lambda 1 \pm \cdot / /$ & $a^{a b / .9 \pm . / 1}$ & ${ }^{b_{1 / N T}} \cdot / r$ & $b_{1 / \wedge q \pm . / \cdot r}$ & $\mathrm{ab}_{\Gamma / / 9 \pm} \cdot / \mathrm{\Delta}$ & $b_{Y / \cdot} q_{ \pm} \cdot / r$ & ضريب تبديل غذايى \\
\hline
\end{tabular}

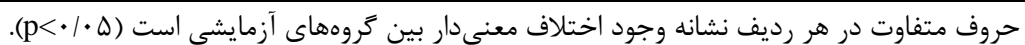

جدول س- تركيب شيميايى (درصد) لاشه فيلماهى (H. huso) جوان تغذيهشده با جيرههاى حاوى يودر سويا و مكمل آنزيمى بهمدت rا هفته

\begin{tabular}{|c|c|c|c|c|c|c|c|c|c|}
\hline \multicolumn{9}{|c|}{ جيره هاى آزمايشى } & \\
\hline 9 & $\Lambda$ & V & 4 & $\Delta$ & f & $r$ & $r$ & 1 & \\
\hline $\mid N / F r \pm \cdot \cdot \cdot \Delta^{d}$ & $\mid N / q 4 \pm \cdot / \cdot f^{b c}$ & $19 / \cdot 1 \pm \cdot / 1 f^{\mathrm{bc}}$ & $19 / \sqrt{ } 9 \pm \cdot 1 \cdot 9^{\mathrm{a}}$ & $\mid V / V 9 \pm .1 .9^{\mathrm{e}}$ & $1 / / 99 \pm \cdot / \cdot 4^{b c}$ & $r \cdot / \cdot \Lambda \pm \cdot / r r^{a}$ & $19 / \pi \pm \cdot / \varepsilon^{b}$ & $1 \mathrm{~N} / 9 \pm \cdot / 19^{\mathrm{cd}}$ & يروتئين \\
\hline $11 / V 4 \pm \cdot / 1$ & $11 / r \Delta \pm \cdot / 19^{\mathrm{cd}}$ & $11 / 4 q \pm \cdot / \cdot 9^{d}$ & $11 / r q \pm \cdot / \cdot r^{\mathrm{cd}}$ & $\mid 1 / V 1 \pm \cdot / 1 r^{\mathrm{ab}}$ & $11 / 4 \cdot \pm \cdot / 4 \cdot$ bcd & $11 / \cdot \wedge \pm \cdot / \cdot \gamma^{d}$ & $11 / r t \pm \cdot 11 \cdot \mathrm{cd}$ & $11 / 99 \pm \cdot / \cdot v^{\mathrm{abc}}$ & جربى \\
\hline$Q \Delta / \Delta T \pm \cdot / T$ & $9 \Delta / 9 \varphi \pm 1 / \cdot \Delta$ & $\varphi \Delta / \Delta \cdot \pm \cdot / \Delta \Delta$ & $G \Delta / G T \pm \cdot / \uparrow \Lambda$ & $99 / 11 \pm \cdot / 99$ & $g F / \Lambda I \pm \cdot / V r$ & QD/ITE./.1 & $9 \Delta / \& \varphi \pm \cdot / f \mid$ & $\varphi \Delta / \Delta \Lambda \pm \cdot / \uparrow \Lambda$ & رطوبت \\
\hline$T / l f \pm \cdot / \cdot r$ & $r / \mid V \pm \cdot / \cdot 1$ & $r / / r \pm \cdot / \cdot V$ & $r / 11 \pm \cdot / \cdot 9$ & $r / 1 \wedge \pm \cdot / \cdot r$ & $T / 19 \pm \cdot / \cdot 1$ & $r / r \mid \pm \cdot / \cdot r$ & $r / / \varepsilon \pm \cdot / \cdot V$ & $r / \cdot १ \pm / \cdot \wedge$ & خاكستر \\
\hline
\end{tabular}

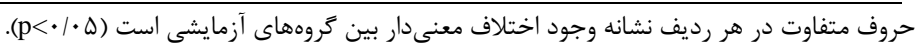

جدول F إروفيل اسيدهاى جرب (ميلى مكمل آنزيمى

\begin{tabular}{|c|c|c|c|c|c|c|c|c|c|}
\hline \multirow[b]{2}{*}{9} & \multirow[b]{2}{*}{$\wedge$} & \multicolumn{8}{|c|}{ جيره هاى آزمايشى } \\
\hline & & v & 4 & $\Delta$ & f & r & r & 1 & اسيد هاى جرب \\
\hline $1 / 4$ & $1 / \pi V$ & $1 / 1$ & $1 / 48$ & $1 / V 1$ & $1 / \cdot 1$ & $1 / \pi \Delta$ & $1 / V F$ & $1 / \pi 4$ & مريستيك اسيد (C14:0) \\
\hline$\cdot / 11$ & $\cdot / / V$ & $\cdot / T \Delta$ & . /Tt & $\Delta / T)$ & $\cdot 191$ & $1 / T \Delta$ & I/QT & $1 / \Delta V$ & مريستولئيك اسيد (C14:1n-5) \\
\hline $19|9|$ & $19 / \cdot r$ & $|V / T|$ & $19 / 94$ & $19 / 49$ & $I V / I Q$ & IV/G. & IE/VT & ID/Tr & يالميتيك اسيد (C16:0) \\
\hline r/A & T/VD & $r / \cdot r$ & r/৭9 & $\Gamma / 9 \Delta$ & $r / T^{4}$ & $r / D \mid$ & 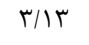 & $T / V I$ & يالميتولئيك اسيد (C16:1n-7) \\
\hline$F / \Delta F$ & $F / I V$ & $\Delta / \cdot F$ & G/VD & $r / v \Delta$ & F/9. & $\varphi / \Delta \Delta$ & $r / 4 \Delta$ & r/AD & استئاريك اسيد (C18:0) \\
\hline rr/VG & rT/VA & Tr/Tt & Tr/IF & rq/V. & rq/19 & rI/1 & Tr/GG & rive & واكسنيك اسيد (C18:1n-7) \\
\hline$\mu / \cdot$ & r/gT & T/AV & T/QT & T/VF & r/99 & $r / 91$ & T/VT & $r / V r$ & اولئيك اسيد (C18:1n-9) \\
\hline $11 / r V$ & $1 N / T$ & $|N / r|$ & Ir/Ir & $19 / 48$ & $I F / F T$ & $10 / 09$ & IV/Tr & $\mid \mathrm{V} / \cdot \mathrm{I}$ & لينولئيك اسيد (C18:2n-6Cis) \\
\hline$r / 9 r$ & $r / 9$. & $r / 9 \Gamma$ & $1 / V \Delta$ & $r / \Delta \Delta$ & $r / r \Delta$ & $r / \pi \cdot$ & $r / \cdot r$ & T/VG & لينولنيك اسيد (C13:3n-3) \\
\hline .111 & $\cdot 111$ & .1 .9 & $\cdot / 1 \mathrm{~V}$ & $.1 \cdot 9$ & $\cdot / 11$ & $\cdot / 1$ & $.1 \cdot 4$ & r & آراشيديك اسيد (C20:0) \\
\hline $1 / 1 r$ & $1 / \pi r$ & $1 / 1 r$ & $1 / 94$ & $1 / 19$ & $1 / 1 F$ & $1 / 1 r$ & $1 / \cdot 1$ & $1 / \pi \wedge$ & ايكوزنوئيك اسيد (C20:1n-9) \\
\hline$\cdot 194$ & .194 & $1 / \cdot$ & $1 / 1 r$ & $\cdot / 4 r$ & $\cdot / \Lambda \Delta$ & $\cdot / 4$ & $\cdot / 4 V$ & $\cdot \mid \Delta S$ & ايكوزا دى انوئيك اسيد (C20:2n-6) \\
\hline $1 / 49$ & $1 / V$ & $1 / V \wedge$ & $1 / 9 V$ & $\cdot / v 9$ & $1 / V$ & $1 / \Delta 9$ & $1 / \cdot r$ & $1 / \pi \cdot$ & آراشيدونيك اسيد (620:4n-6) \\
\hline . & $\cdot / \pi \Delta$ & $\cdot / 1 r$ & .1 .9 & $\cdot 111$ & .119 & $\cdot / 14$ & $\cdot \pi r$ & $\cdot / 1 F$ & ايكوزا ترينوئيك اسيد (C20:3n-3) \\
\hline r/Tt & $r / \vee q$ & $r / \cdot V$ & $r / r q$ & ז/ץq & $r / 99$ & r/AT & $T / K \Delta$ & T/QT & ايكوزاينتانوئيك اسيد (C20:5n-3) \\
\hline$\cdot / \pi \Delta$ & $\cdot / 1 \Lambda$ & $\cdot / \pi$ & $1 / \cdot 1$ & $r / 9 \Lambda$ & $1 / 11$ & $\cdot \operatorname{l\Lambda }$ & $1 / \% \Lambda$ & $r / 4$. & دوكوزانوئيك اسيد (C22:0) \\
\hline N/द. & $\Lambda / r \Delta$ & $9 / 1 \cdot$ & $9 / 44$ & $9 / \wedge \wedge$ & $11 / 94$ & $11 / 1 \mathrm{~V}$ & $9 / \Delta F$ & $11 / \cdot r$ & دوكوزاهگَزانوئيك اسيد (C20:6n-3) \\
\hline$r \mu / \cdot 1$ & $r I / A \Delta$ & $r F / \Delta \Delta$ & $r q / 14$ & TF/QT & $r \varphi / \cdot \Delta$ & TF/TH & 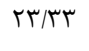 & 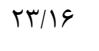 & مجموع اسيد هاى حرب اشباع \\
\hline $4 \cdot 119$ & $r q / \Delta F$ & $r q / 4 q$ & $4 \cdot / 4 \varepsilon$ & $\mid+1 / 4 \varepsilon$ & rq/. & $r 9 / 91$ & $f \cdot|9|$ & $r \cdot 1 \cdot \Delta$ & مجموع اسيد هاى جرب تك غير اشباع \\
\hline$r \Delta / F q$ & $r \Delta / r)$ & ret/gr & rQ/Ar & $r M / Q 1$ & $r \Delta / \uparrow$. & $r F / 9 v$ & MF/AV & T & مجموع اسيد هاى جرب حند غير اشباع \\
\hline $14 / 9 V$ & $\mid f / r q$ & $11 / 94$ & $1 \% / 09$ & $10 / 94$ & IN/FT & IV/TK & $191 \cdot 4$ & IV/FE & مجموع اسيد هاى خرب امخا-r \\
\hline$r \cdot / 4 V$ & $r \cdot / A r$ & $r \cdot 199$ & $19 / \pi r$ & $\mid V / \Delta \Lambda$ & $19 / 9 V$ & $I V / V \Delta$ & IN/Ar & IN/VV & مجموع اسيد هاى جرب امكا-4 \\
\hline$\cdot / \mathrm{VH}$ & .199 & $\cdot 1 \Delta \Delta$ & $\cdot \mid \Lambda r$ & $\cdot 19$. & $1 / \cdot 1$ & $\cdot / 9 \mathrm{~V}$ & $\cdot / 1 \Delta \omega$ & . 194 & اسيد هاى خرب امعا-؟r/اسيدهاى خرب امعا-4 \\
\hline
\end{tabular}


جدول ه- تغيير جوامع ميكروبى روده (واحد تشكيلدهنده كلنى در ترم) فيلماهى (H. huso) جوان در ياسخ به جايكزينى بودر سويا با يودر ماهى بعد از آ هفته تغذيه

\begin{tabular}{|c|c|c|c|c|c|c|c|c|c|}
\hline \multicolumn{10}{|c|}{ جيره هاى آزمايشى } \\
\hline 9 & $\wedge$ & v & 4 & $\Delta$ & f & r & $r$ & 1 & \\
\hline${ }^{a} \Delta / 91 \pm \cdot / \cdot 1$ & ${ }^{\mathrm{a}} \mathrm{\omega} / \Lambda \Lambda \pm \cdot / \cdot \cdot$ & ${ }^{\mathrm{a}} \mathrm{Q} / \mathrm{q} \pm \pm \cdot / \cdot \mathrm{f}$ & ${ }^{\mathrm{a}} \mathrm{D} / \mathrm{AV} \pm \cdot / \cdot 9$ & ${ }^{\mathrm{a}} \Delta / \Lambda \Lambda \pm \cdot / \cdot 9$ & ${ }^{\mathrm{a}} \mathrm{Q} / \wedge \vee \pm \cdot / /$. & ${ }^{b} \Delta / r \bigvee \pm \cdot / \cdot r$ & ${ }^{\mathrm{b}} \Delta / \mathrm{T} \Psi \pm \cdot / \mathrm{T}$ & $b \Delta / 19 \pm \cdot / 111$ & $\begin{array}{l}\text { لاكتوكو كوس لاكتيس } \\
\text { (Lactococcus lactis) }\end{array}$ \\
\hline$a v / 4 \cdot \pm \cdot / 11$ & $\bullet q \mid \Lambda \Lambda \pm . / .9$ & BV/TrE./.G & $c 9 / 9 \cdot \pm \cdot / \cdot 1$ & $c q \mid \wedge \vee \pm \cdot / . \cdot$ & $c 9 / 94 \pm \cdot / \cdot 1$ & ${ }^{\mathrm{d}} \Delta / 9 \Delta \pm \cdot / 1 \mathrm{~T}$ & ${ }^{\mathrm{d}} \Delta / \mathrm{YT}^{\mathrm{H}} \pm \cdot / \cdot 9$ & $\mathrm{~d} \Delta / \varphi \mathrm{f} \pm \cdot / \cdot \mathrm{F}^{\mathrm{f}}$ & $\begin{array}{c}\text { لاكتوباسيلوس كارواتوس } \\
\text { (Lactobacillus curvatus) }\end{array}$ \\
\hline${ }^{\mathrm{ab}} \Delta / \wedge \varsigma \pm \cdot / \cdot \uparrow$ & ${ }^{b c} \Delta / \wedge \top_{ \pm} \cdot / \cdot \varphi$ & ${ }^{b c} \Delta / \Lambda T \pm \cdot / \cdot Y$ & ${ }^{b} \Delta / \Lambda F \pm \cdot / \cdot r$ & ab $\Delta / \Lambda \Lambda \pm \cdot / \cdot \uparrow$ & ${ }^{a} \Delta / q \Psi \pm . / . r$ & $\mathrm{de} \Delta / ৭ ९ \pm \cdot / \cdot 1$ & ${ }^{\mathrm{cd}} \Delta / V \uparrow \pm \cdot /$. & $\mathrm{e} \Delta / G \uparrow \pm \cdot / T$ & $\begin{array}{r}\text { يديكو كوس ينتاساسئوس (Pediococcus pentosaceus ) } \\
\text { (Pens }\end{array}$ \\
\hline $\mathrm{a} / \cdot 1 \pm \cdot / 1 \mathrm{f}$ & ac/ $/ \Lambda \Delta \pm \cdot / \cdot r$ & $\operatorname{ag} / 9 \vee \pm \cdot / / \Delta$ & 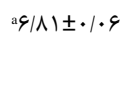 & $\mathrm{a} \mid \wedge \wedge \pm \cdot / \cdot$ & ac/ $\mid \wedge f \pm \cdot / \cdot r$ & ${ }^{\mathrm{b}} \Delta / V T \pm \cdot / \cdot \Lambda$ & ${ }^{b} \Delta / V r \pm \cdot / \cdot r$ & ${ }^{b} \Delta / 99 \pm \cdot / \cdot \Delta$ & لاكتوباسيلوس يلانتاروم \\
\hline aN/DTE./.t & abN/TIE•//r & $a b N / r \mid \pm \cdot / 1 \Lambda$ & cV/\&TE. & bc $/ / \wedge \pm \pm \cdot / \cdot ケ$ & bc $/ / q \cdot \pm \cdot / V \cdot$ & $\mathrm{d} \mathscr{G} / \Delta \mathscr{\Phi} \pm \cdot / \cdot \Lambda$ & $\mathrm{d} \varphi / \mathrm{r} \Lambda \pm \cdot / \cdot r$ & $\mathrm{~d} g / f t \pm \cdot / \Lambda r$ & مجموع باكترى هاى هوازى \\
\hline a $/ \wedge 9 \pm \cdot / \cdot \uparrow$ & ab $/ / \vee १ \pm \cdot / /$. & aN/AF士 $\pm / 11$ & $\mathrm{c} / \mathrm{rr} \pm \cdot / \cdot 9$ & ${ }^{\mathrm{bc}} \Lambda / \uparrow \Lambda \pm \cdot / \cdot \uparrow$ & ${ }^{c} \mathcal{N} / r q \pm \cdot / r V$ & $\mathrm{~d} q / \Lambda \Lambda \pm \cdot / \mid r$ & $\mathrm{~d} q / \vee १ \pm \cdot /$ & $\mathrm{d} \boldsymbol{q}|\Lambda \Delta \pm \cdot /|$. & مجموع باكترىهاى بىهوازى \\
\hline
\end{tabular}

Lim et al., ) نكرد (Silva-Carrillo et al., 2012). ليم و همكاران

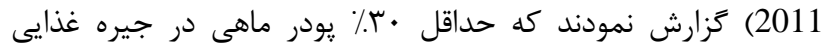

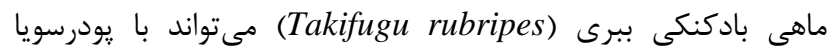

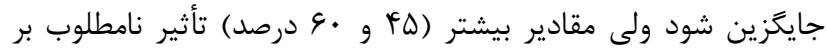
عملكرد رشد و راندمان غذايى داشت. بلطوركلى، تفاوت در ميزان

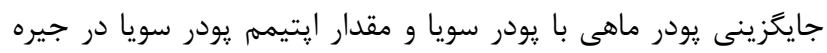

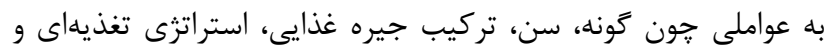

مقدار عوامل ضد تغذيهاى بستخى دارد (Lin and Li, 2011).

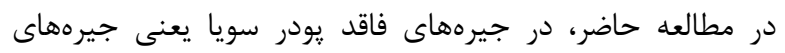

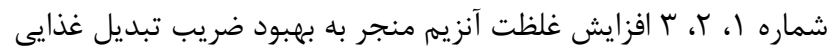

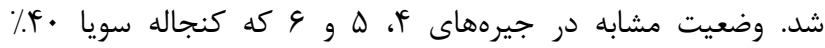

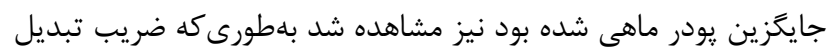

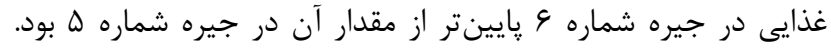
نتايج مشابه توسط شاى و همكاران (Shi et al., 2016) نيز كزارش داره

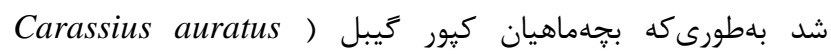
(gibelio

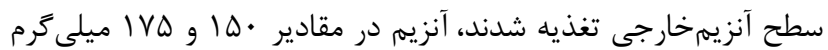

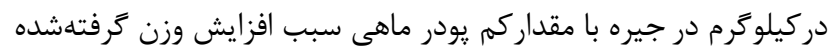
و كاهش ضريبتبديل غذايى در مقايسه با كروه كنترل كرديد. همرجنين

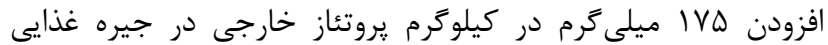

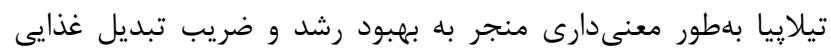

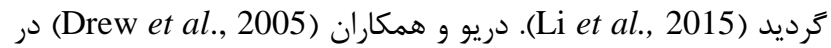
قزلآلاى رنكين كمان و كارتر و همكاران (Carter et al., 1994) در در دران

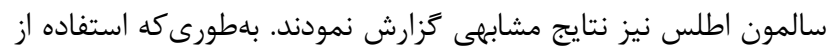

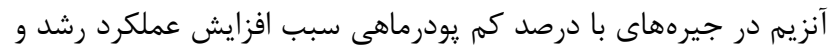

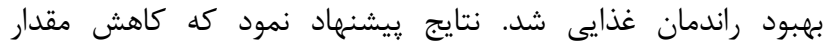

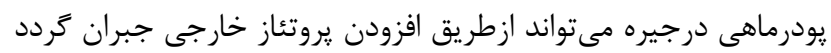

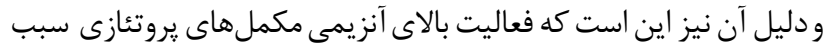

| ب بحث و نتيجه

در مطالعه حاضر، با افزودن آنزيم به ميزان ك كَرم در كيلوَّرم به جيره

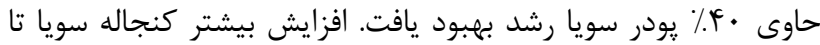

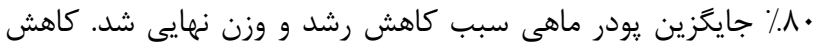

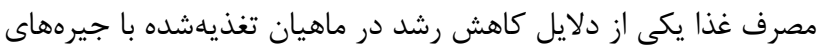
حاوى يروتئين كياهى از جمله يروتئين سويا (Espe et al., 2006)

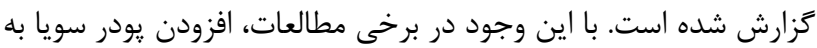
Lيره سبب كاهش مصرف غذا نشد ( Lin and Li, 2011; Gomes et al., 1993 (al. كاهش رشد و وزن نهايى در تغذيه با يودر سويا بهدلايلى

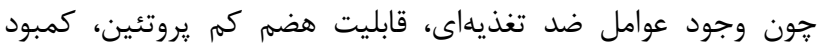

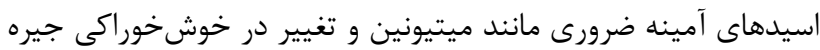

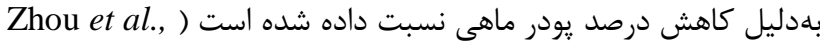
2011; Silva-Carrillo et al., 2012 بهعنوان شاخص در بيشبينى مصرف غذا و تفاوت رشد در ماهيان

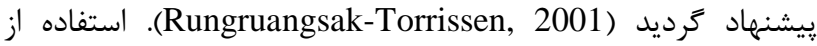
يودر سويا در جيره با تأثير بر كاهش فعاليت آنزيمهاى بروتئئازى روده و

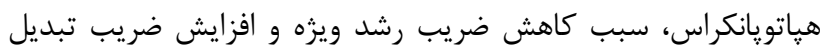

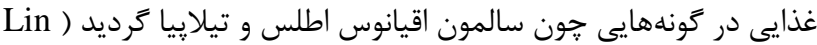
and Li, 2011; Krogdahl et al., 2003 آنزيمهاى تروتئازى بلوجود عوامل ضد تغذيهاى در يودر سويا نسبت آندات داده شد (Pavasovic et al., 2004). در تغذيه آبزيان، مقدار جايكزينى با يودر سويا بسيار حائز اهميت است. در ماهى تيلإييا، لين و لى (Lin and Li, 2011) نشان دادند كه رابطه معكوسى بين سطوح يودرسويا و رشد وجود داشته است بلططورىكه جايكزينى كامل يودر

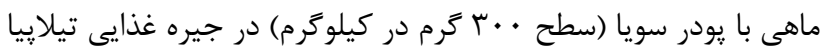
سبب كاهش عملكرد رشد شد، ولى وقتى درصد إند جايكزينى بردي برابر يا كمتر از VD٪ بود تفاوت معنىدارى با كروه كنترل مشاهد نشد. در درد

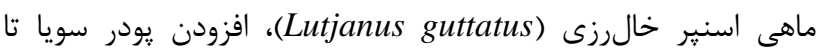

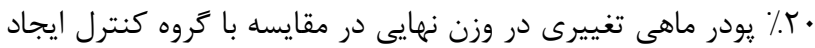


جند غيراشباع و اسيدهاى خرب اشباع قرار داشتهاند. اين الكَوى

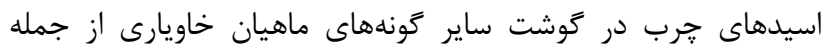
تاسماهى سيبرى (Acipenser baerii) در مطالعه باديانى و همارئ ماران (Badiani et al., 1997)، هيبريد بين تاسماهى ناكارى و تاسماهي (Aciperiper baerii) سيبرى (Acipenser naccarix Acipenser baerii) بهوسيله واكارو (B) باري و همكاران (Vaccaro et al., 2005) و هيبريد تاس ماهى سيبرى با تاس ماهى سبز (Acipenser baerii XAcipenser medirostris)

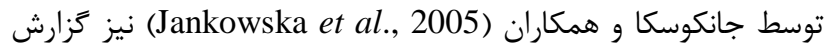

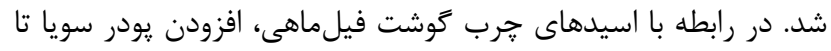
•1. جايكزين يودر ماهى و بدون افزودن آنزيم خارجى (تيمار شماره

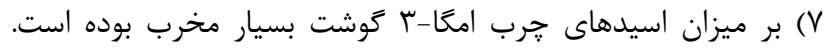

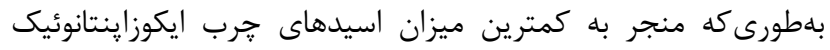

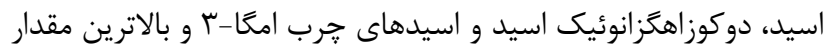

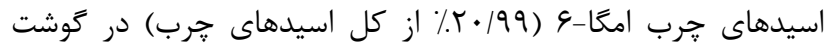

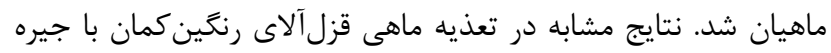

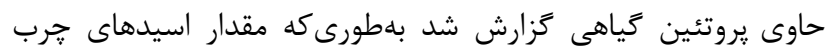

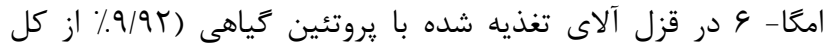

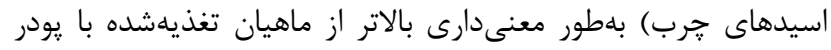

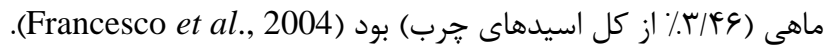

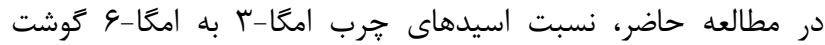

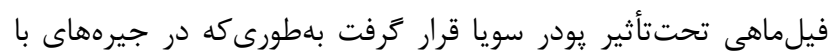

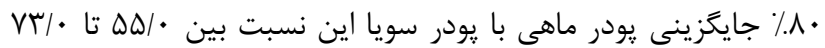

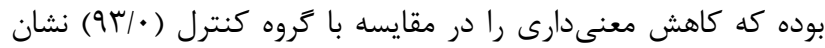

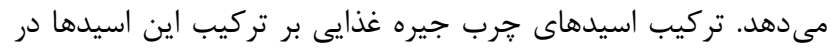

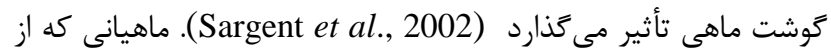
جيرههاى حاوى يروتئين خياهى از جمله يروتئين سويا استفاده

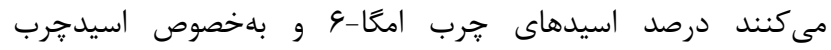

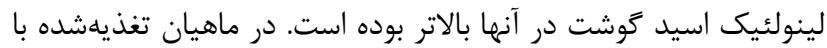

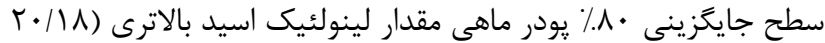

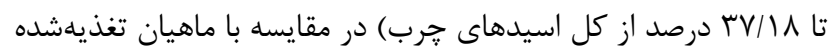

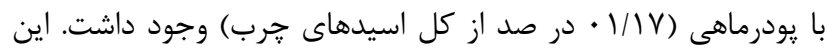
نتيجه با نتايج بهدست آمده توسط فرانسيسكو و همكاران ( Francesco (et al., 2004

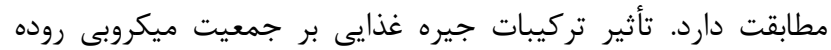

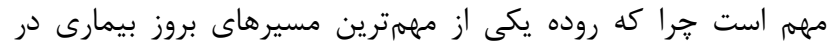

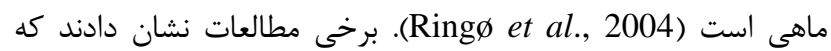

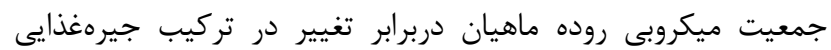

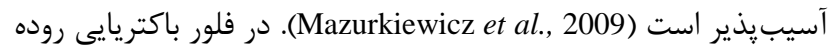

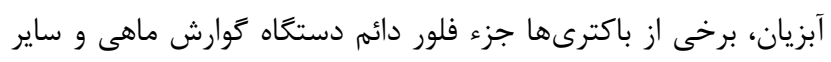

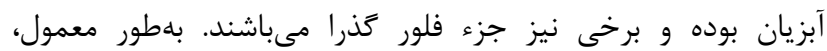

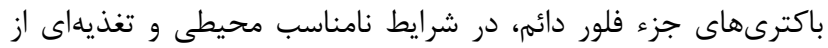

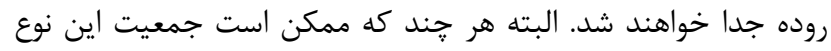

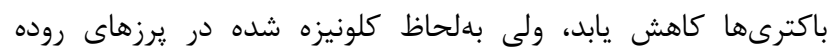
هميشه وجود خواهند داشت. در خصوص باكترىهاى لاكتيك برخى از باز
سبب افزايش قابليت استفاده از يروتئين سويا در ماهى مى كردد ) Shi

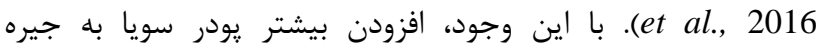

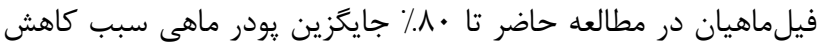

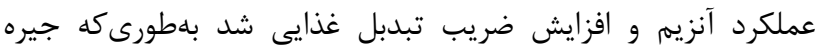

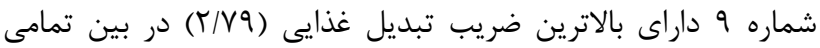
تيمارها بود. ليمينوكس و همكاران (Lemieux et al., 1999) بيان كردند كه يروتئين سويا بهطور معمول داراى بازدارندههاى يروتئاز

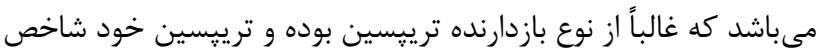

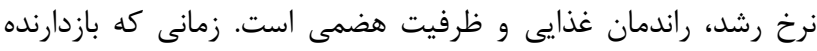

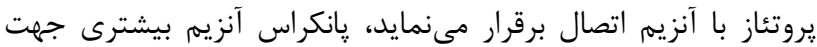

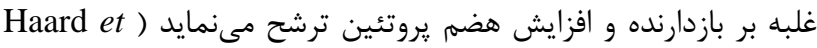

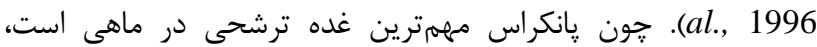

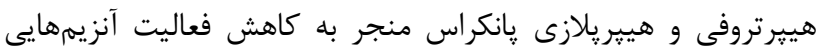

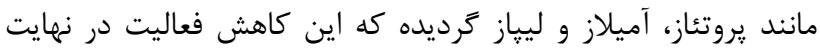

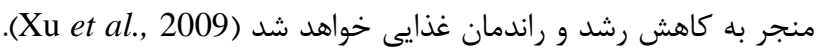
نتايج مشابه در تاسماهى آمور نيز مشاهده شد (Xu et al., 2012)

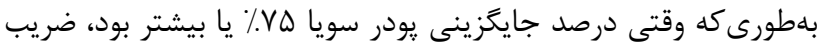

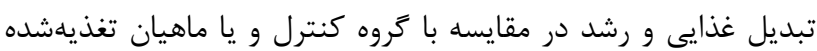

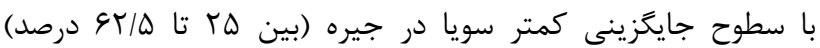

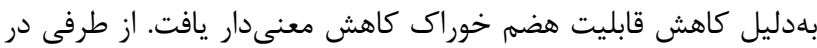

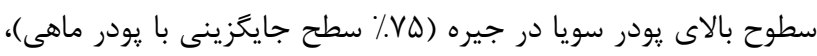

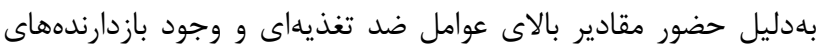

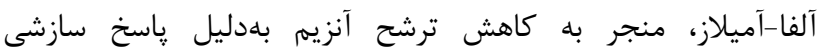

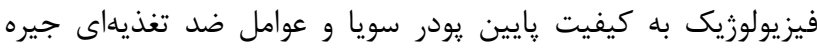

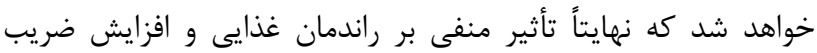

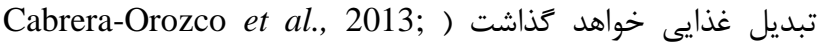

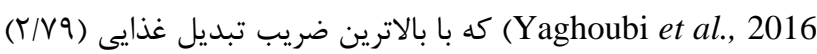

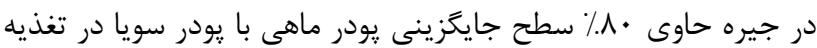
فيلماهى يعنى تيمار شماره 9 در اين مطالعه مطابقت دارئ دارد. ضرديب

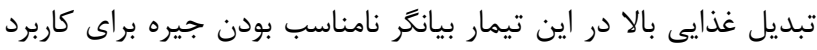
در تغذيه فيلماهى مىباشد. مقدار جربى كوشت فيلماهى تحت تأثير جيرههاى غذايى قرار

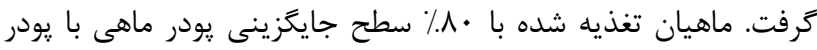

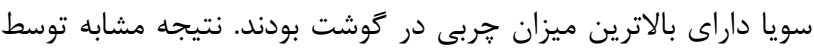
يعقوبى و همكاران (Yaghoubi et al., 2016) در تغذيه بجهماهيان

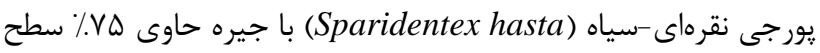

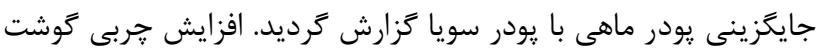

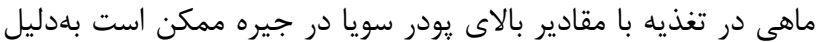

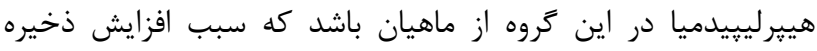

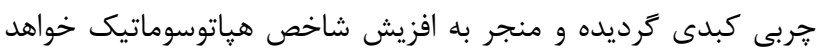

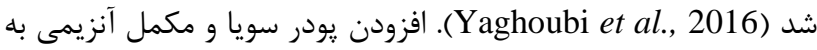

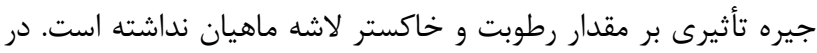
كوشت فيلماهيان، اسيدهاى جرب تكغيراشباع بيشترين مقدار

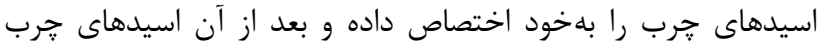


mazandarani@gmail.com

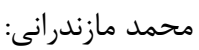

\section{REFERENCES}

AOAC. 1990. Official Methods of Analysis of AOAC.

Vol.1, $15^{\text {th }}$ Edition, Association of Official Analytical Chemists, Arlington, VA, USA.

Badiani A., Stipa S., Nanni N., Gatta P.P., Manfredini M. 1997. Physical indices, processing yields, compositional parameters and fatty acid profile of three species of cultured sturgeon (Genus Acipenser). Journal of the Science of Food and Agriculture, 74: 257-264.

Cabrera-Orozco A., Jiménez-Martínez C. Dávila-Ortiz G. 2013. Soybean: Non-Nutritional Factors and Their Biological Functionality. In: El-Shemy HA (Eds.). Soybean Bio Active Compounds, Intech Open Access Publisher, pp: 387-410.

Carter C.G., Houlihan D.F., Buchanan B., Mitchell A.I. 1994. Growth and feed utilization efficiencies of seawater Atlantic salmon, Salmo salar L., fed a diet containing supplementary enzymes. Journal of Aquaculture and Fisheries Management, 25: 37-46.

Castillo S., Gatlin D.M. 2015. Dietary supplementation of exogenous carbohydrate enzymes in fish nutrition: A review. Journal of Aquaculture, 435: 286-292.

Drew M.D., Racz V.J., Gauthier R., Thiessen D.L. 2005. Effect of adding protease to coextruded flax: pea or canola: pea products on nutrient digestibility and growth performance of rainbow trout (Oncorhynchus mykiss). Journal of Animal Feed Science and Technology, 119: 117-128.

Esmailli P., Mozaffari N., Masoleh A. 2010. Isolation and identification of lactic acid bacteria from Persian sturgeon (Acipenser persicus). Journal of Biological Science, 3: 13-18.

Espe M., Lemme A., Petri A., El-Mowafi A. 2006. Can Atlantic salmon grow on diets devoid of fish meal? Aquaculture, 255: 255-262.

Farhangi M., Carter C.G. 2007. Effect of enzyme supplementation to dehulled lupin-based diets on growth, feed efficiency, nutrient digestibility and carcass composition of rainbow trout Oncorhynchus mykiss(Walbaum). Journal of Aquaculture Research, 38: 1274-1282.

Francesco M., Parisi G., Medale F., Lupi P., Kaushik S.J., Poli B.M. 2004. Effect of long-term feeding with a plant protein mixture based diet on growth and body/fillet quality traits of large rainbow trout (Oncorhynchus mykiss). Journal of Aquaculture, 236: 413-429.

Francis G., Makkar H.P.S., Becker K. 2001. Antinutritional factors present in plant-derived alternate fish feed ingredients and their effects in fish. Journal of Aquaculture, 199: 197-227.

Gatlin D.M., Barrows F.T., Brown P., Dabrowski K., Gaylord T.G., Hardy R.W., Herman E., Hu G.S., Krogdahl A., Nelson R., Overturf K., Rust M., Sealey W., Skonberg D., Souza E.J., Stone D., Wilson R., Wurtele E. 2007. Expanding the utilization of sustainable plant productsin aqua feeds, a review. Aqua-
منابع از آنها بهعنوان فلور دائم و اكثر منابع نيز از آنها بهعنوان فلور

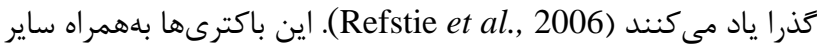

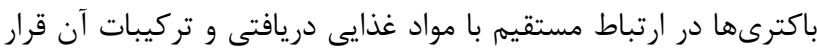

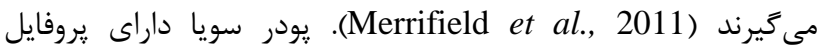
مختلفى از اسيدهاى آمينه بوده كه منبع مناسبى براى باكترىهاى

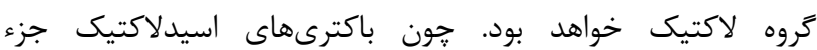
باكترىهاى يرنياز بوده از اينرو به لحاظ فراهم بودن شرايط مذكور بر برد

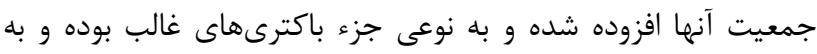

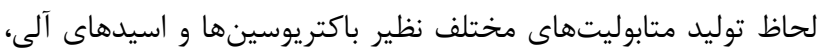
در رقابت غذايى با ساير باكترىها موفقتر عمل كرده و با مهيا شدن

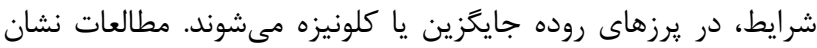

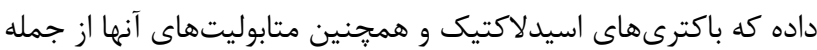
باكتريوسينها نقش مهمى در عملكرد هضمى ميزبان، مقاومت لايه

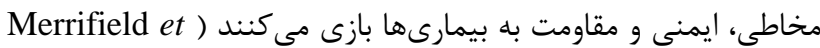

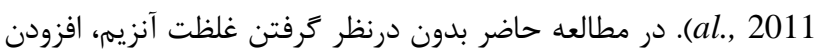

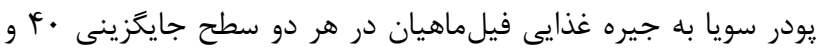

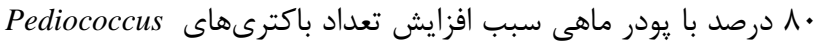
Lactococcus lactis ،Lactococcus lactis ،pentosaceus Lactobacillus plantarum, شد. از سويى ديكر، آنزيمهاى خارجى به شكل مكمل با تجزيه اجزاى جيره سبب تبديل آن به تركئ تركيبات آنسات

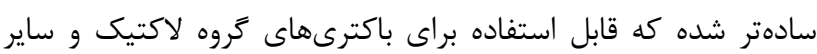

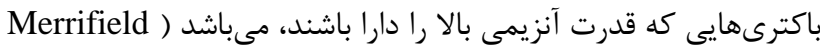

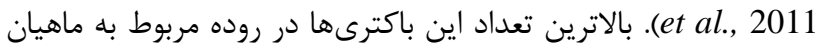

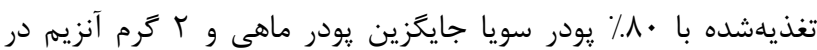
كيلوكرم يعنى تيمار 9 اتفاق افتاد.

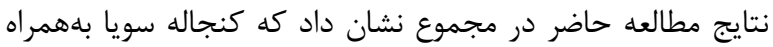

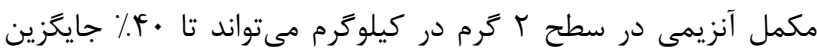

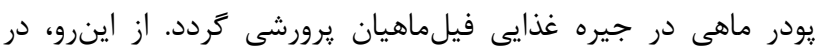

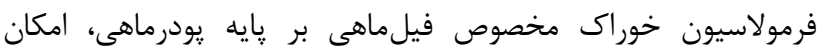

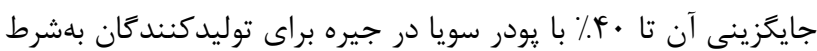
استفاده از مكمل آنزيمى وجود خواهد داشت بودر بان.

$$
\text { ه | لهار | تشكر و قدردانى }
$$

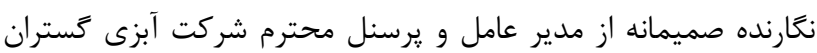

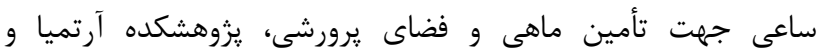

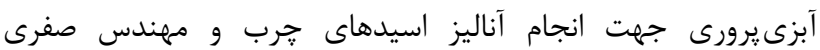

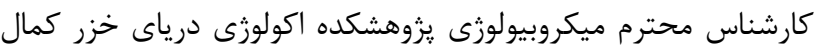

$$
\text { تشكر و امتنان را دارد. }
$$

$$
\text { يست الكترونيك نويسندكان }
$$

msohrabnezhad@yahoo.com

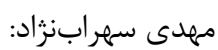
sudagar_m@yahoo.com

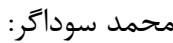
mrghomi@gmail.com

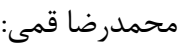


culture Research, 38: 551-579.

Ghomi M.R., Shahriyari R., Faghani Langroudi H., Nikoo M., Von Elert E. 2012. Effects of exogenous dietary enzyme on growth, body composition, and fatty acid profiles of cultured great sturgeon Huso huso fingerlings. Journal of International Aquaculture, 20: 249-254.

Gomes E.F., Corraze G., Kaushik S.J. 1993. Effects of dietary incorporation of a co-extruded plant protein (rapeseed and peas) on growth, nutrient utilization and muscle fatty acid composition of rainbow trout (Oncorhynchus mykiss). Journal of Aquaculture, 113: 339-353.

Haard N.F., Dimes L.E., Arndt R.E., Dong F.M. 1996. Estimation of protein digestibility. IV. Digestive proteinases from the pyloric caeca of Coho salmon (Oncorhynchus kisutch) fed diets containing soybean meal. Journal of Comparative Biochemistry and Physiology B, 115(4): 533-540.

Hallajian A., Kazemi R., Yosefi Jourdehi A. 2011. Effect of clove (Caryophillium aromaticus) powder on aneshthesia and recovery of farmed 4 years Beluga (Huso huso). Journal of Fisheries, Islamic Azad University, Azadshahr Branch, 5: 133-141. (In Persian).

Heikkinen J., Vielma J., Kemilainen O., Tiirola M., Eskelinen P., Kiuru T., Navia-paldanius D., Wright A.V. 2006. Effect of soybean meal based diet on growth performance, gut histology and intestinal microbiota of juvenile rainbow trout (Oncorhynchus mykiss). Journal of Aquaculture, 261: 259-268.

Jankowska B., Kolman R., Szczepkowski M., Zmijewski T. 2005. Production value, chemical composition and color of fillets of the reciprocal hybrid of Siberian sturgeon with green sturgeon (Acipenser baerii Br $\times$ Acipenser medirostris Ayres). Journal of Animal Science, 50: 220-225.

Kolkovski S., Tandler A., Kissil G. W., Gerteler A. 1993. The effect of dietary exogenous digestive enzymes on ingestion, assimilation, growth and survival of gilthead seabream (Sparus aurata,) larvae. Journal of Fish Physiology and Biochemistry, 12: 203-209.

Krogdahl A., Bakke-McKellep A.M., Baeverfjord G. 2003. Effects of graded levels of standard soybean meal on intestinal structure, mucosal enzyme activities, and pancreatic response in Atlantic salmon (Salmo salar L.). Journal of Aquaculture Nutrition, 9: 361-371.

Lee S.M. 2002. Apparent digestibility coefficients of various feed ingredients for juvenile and grower roach fish (Sebastess chlegeli). Journal of Aquaculture, 207: 79-95.

Lemieux H., Blier P.U., Dutil J.D. 1999. Do digestive enzymes set a physiological limit on growth rate and food conversion efficiency in the Atlantic cod (Gadus morhua). Journal of Fish Physiology and Biochemistry, 20: 293-303.

Li X.Q., Chai X.Q., Liu D.Y., Chowdhury M.A.K., Leng X.J. 2015. Effects of temperature and feed processing on protease activity and dietary protease on growths of white shrimp, Litopenaeus vannamei, and tilapia,
Oreochromis niloticus $\times$ O. aureus. Aquaculture Nutrition, 22(6): 1283-1292.

Lim S.J., Kim S.S., Ko G.Y., Song J.W., Oh D.H., Kim J.D., Kim J.U., Lee K.J. 2011. Fish meal replacement by soybean meal in diets for Tiger puffer, Takifugu rubripes. Journal of Aquaculture, 313: 165-170.

Lin S., Li L. 2011. Effects of different levels of soybean meal inclusion in replacement for fish meal on growth, digestive enzymes and transaminase activities in practical diets for juvenile tilapia, Oreochromis niloticus $\times O$. aureus. Journal of Animal Feed Science and Technology, 168: 80-87.

Mazurkiewicz J., Przybyl A., Golski J. 2009. Usability of some plant protein ingredients in the diets of Siberian sturgeon Acipenser baerii Branndt. Archives of Polish Fisheries, 17:45-52.

Merrifield D.L., Olsen R.E., Myklebust R., Ringø E. 2011. Dietary effect of soybean (Glycine max) products on gut histology and micro biota of fish. In: El- Shemy HA (Eds.). Soybean Bio Active Compounds, Intech Open Access Publisher, pp: 232250.

Miquel M., Browse J. 1992. Arabidopsis mutants deficient in polyunsaturated fatty acid synthesis. The Journal of Biological Chemistry, 267: 1502-1509.

Ogunkoya A.E., Page G.I., Adewolu M.A., Bureau D.P. 2006. Dietary incorporation of soybean meal and exogenous enzyme cocktail can affect physical characteristics of fecal material egested by rainbow trout (Oncorhynchus mykiss). Journal of Aquaculture, 254: 466-475.

Pavasovic M., Richardson N.A., Anderson A.J., Mann D., Mather P.B. 2004. Effect of pH, temperature and diet on digestive enzyme profiles in the mud crab, Scylla serrata. Journal of Aquaculture, 242: 641-654.

Qinghui A., Kangsen M., Wenbing Z., Wei X., Beiping T., Chunxiao Z., Huitao L. 2007. Effects of exogenous enzymes (phytase, non-starch polysaccharide enzyme) in diets on growth, feed utilization, nitrogen and phosphorus excretion of Japanese seabass, Lateolabrax japonicas. Journal of Comparative Biochemistry and Physiology, 147: 502-508.

Refstie S., Landsverk T., Ring $\varnothing$ E., Sundby A., Shearer K.D., Kroghdahl Å. 2006. Digestive responses of 1and 2-year-old Atlantic cod (Gadus morhua) fed standard or bioprocessed soybean meal. Aquaculture, 261: 269284.

Ringø E., Jutfelt F., Kanapathippillai P., Bakken Y., Sundell K., Glette J., Mayhew T.M., Myklebust R., Olsen R.E. 2004. Damaging effect of the fish pathogen Aeromonas salmonicida on intestinal enterocytes of Atlantic salmon (Salmo salar L.). Cell and Tissue Research, 318: 305-311.

Rungruangsak-Torrissen K. 2001. Important parameters for growth study. In: The $2^{\text {nd }}$ International Symposium on Cultivation of Salmon II, Bergen, Norway, pp: 710.

Sargent J.R., Tocher D.R., Bell G.J. 2002. The lipids. In: Halver JE, Hardy R (Eds.). Fish Nutrition, $3^{\text {rd }}$ Edition, Academic Press, San Diego, CA, USA, pp: 181-257.

Shi Z., Li X.Q., Kabir Chowdhuryb M.A., Chen J.N., Leng 
X.J. 2016. Effects of protease supplementation in low fish meal pelleted and extruded diets on growth, nutrient retention and digestibility of gibel carp, Carassius auratus gibelio. Journal of Aquaculture, 460: 37-44.

Silva-Carrillo Y., Hernández C., Hardy R.W., GonzálezRodríguez B. Castillo-Vargasmachuca S. 2012. The effect of substituting fish meal with soybean meal on growth, feed efficiency, body composition and blood chemistry in juvenile spotted rose snapper Lutjanus guttatus (Steindachner, 1869). Journal of Aquaculture, 364: 180-185.

Sohrabnezhad M., Sudagar M., Mazandarani M. 2017. Effect of dietary soybean meal and multienzyme on intestine histology of beluga sturgeon (Huso huso). International Aquatic Research, 9: 271-280.

Ustaoglu S., Rennert B. 2002. The apparent nutrient digestibility of diets containing fish meal or isolated soy protein in sterlet (Acipenser ruthenus). International Reviews in Hydrobiology, 87: 577-584.

Vaccaro A.M., Buffa G., Messina C.M., Santulli A., Mazzola A. 2005. Fatty acid composition of a cultured sturgeon hybrid (Acipenser naccari $\times$ A.baerii). Journal of Food Chemistry, 93: 627-631.

Xu B.H., Wang, Y.B., Li J.R., Lin Q. 2009. Effect of prebiotic xylooligosaccharides on growth performances and digestive enzyme activities of allogynogenetic crucian carp (Carassius auratus gibelio). Fish Physiology and Biochemistry, 35: 351357.

Xu Q.Y., Wang C.A., Zhao Z.G., Luo L. 2012. Effects of replacement of fish meal by soy protein isolate on the growth, digestive enzyme activity and serum biochemical parameters for juvenile Amur sturgeon (Acipenser schrenckii). Asian-Australian Journal of Animal Science, 25: 1588-1594.

Yaghoubi M., Torfi Mozanzadeh M., Marammazi J.G., Safari O., Gisbert E. 2016. Dietary replacement of fish meal by soy products (soybean meal and isolated soy protein) in silvery-black porgy juveniles (Sparidentex hasta). Journal of Aquaculture, 464: 50-59.

Ye J., Liu X., Wang Z., Wang K. 2011. Effect of partial fish meal replacement by soybean meal on the growth performance and biochemical indices of juvenile Japanese flounder Paralichthys olivaceus. Journal of Aquaculture International, 19: 143-153.

Yildirim Y.B., Turan F. 2010. Effects of exogenous enzyme supplementation in diets on growth and feed utilization in African cat fish. Clarias gariepinus. Journal of Animal and Veterinary Advances, 2920: 327-331.

Zhou F., Song W., Shao Q., Peng X., Xiao J., Hua Y., Owari B.N., Zhang T., Ng W.K. 2011. Partial replacement of fish meal by fermented soybean meal in diets for black sea bream, Acanthopagrus schlegelii, juveniles. Journal of World Aquaculture Society, 42: 184197.

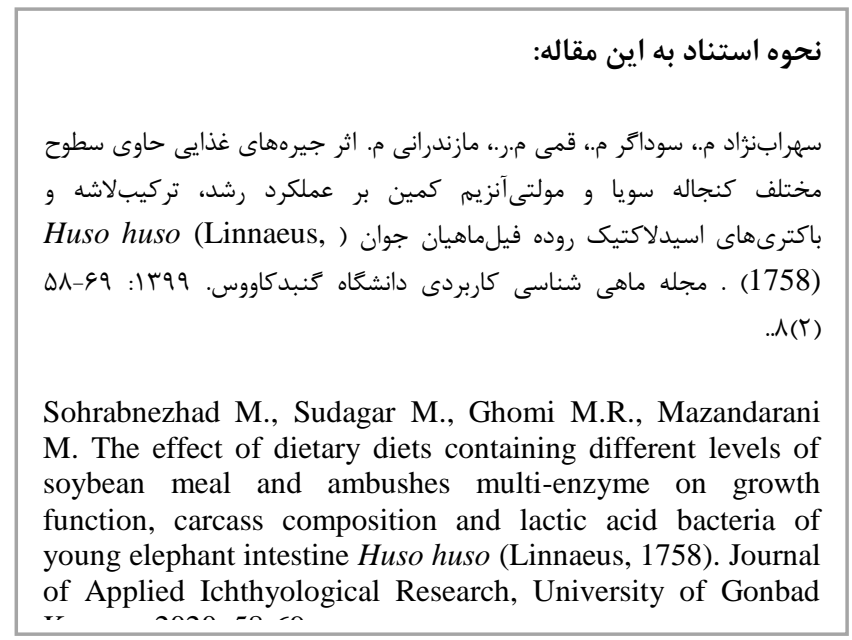

Sohrabnezhad M., Sudagar M., Ghomi M.R., Mazandarani $M$. The effect of dietary diets containing different levels of soybean meal and ambushes multi-enzyme on growth function, carcass composition and lactic acid bacteria of of Applied Ichthyological Research, University of Gonbad 


\title{
Effect of different levels of soybean meal and Kemin multi-enzyme on growth performance, body composition, and gut lactic acid bacteria of juvenile Beluga Huso huso (Linnaeus, 1758)
}

\author{
Sohrabnezhad M${ }^{1}$., Sudagar $M^{* 2}$., Ghomi M.R³., Mazandarani $M^{4}$. \\ ${ }^{1} \mathrm{PhD}$ student in aquaculture, Gorgan University of Agricultural Sciences and Natural Resources, Gorgan, Iran \\ ${ }^{2}$ Associate Prof., Dept. of Aquaculture, Gorgan University of Agricultural Sciences and Natural Resources, Gorgan, Iran \\ ${ }^{3}$ Assistant Prof., Dept. of Aquaculture, Gorgan University of Agricultural Sciences and Natural Resources, Gorgan, Iran \\ ${ }^{4}$ Associate Prof., Dept. of Fisheries, Islamic Azad University, Tonekabon, Mazandaran, Iran
}

\section{Type:}

Original Research Paper

\section{Paper History:}

Received: 9- 11- 2016

Accepted: 28- 2- 2017

\section{Corresponding author:}

Sudagar M. Associate Professor, Department of Aquaculture, Gorgan University of Agricultural Sciences and Natural Resources, Gorgan, Iran

Email: sudagar_m@yahoo.com

\section{Abstract}

The present study aimed to investigate the effects of replacing fish meal with soybean meal and different levels of Kemin multi-enzyme on growth performance, feed efficiency, body composition, fatty acid profile, and gut lactic acid bacteria of beluga sturgeon $(H$. huso). Fish were fed with nine different diets ( $40 \%$ crude protein) including three different replacement levels of fish meal with soybean meal 0 (as control), 40, and 80\% and three different levels of Kemin multi-enzyme 0,1 , and $2 \mathrm{~g} / \mathrm{kg}$. Fish were fed with the experimental diets for 12 weeks at a rate of $1 \%$ of body weight per day. The replacement of fish meal with soybean meal resulted in a reduction in growth performance and the lowest weight gain and the highest feed conversion ratio was observed in the diet with $80 \%$ replacement. The highest weight gain, higher level of enzyme $(2 \mathrm{~g} / \mathrm{kg})$, and lower feed conversion ratio were observed in the diet without soybean meal. Similar results were recorded in treatment with $40 \%$ of soybean meal, indicated the positive effect of utilization of enzyme on growth performance. However, no significant difference was observed in final weight gain among different diets. Use of soybean meal (0 and 40\%) and Kemin multi-enzyme $(2 \mathrm{~g} / \mathrm{kg})$ showed a higher percentage of protein in fish. Fatty acid profiles and lipid content (ranged from 11.08 to $11.74 \%$ ) had significant differences among different treatments. Fish fed with the control group and diets with enzyme supplements (without soybean meal) and diets 4 and $5(0$ and $1 \mathrm{~g} / \mathrm{kg}$ enzyme and $40 \%$ soybean meal) showed the highest level of $n-3$ fatty acids and eicosapentaenoic acid. In contrast, diet containing $80 \%$ soybean meal without enzymes (treatment 7) had the least n-3 fatty acids, eicosapentaenoic acid, and docosahexaenoic acid. An increment was observed in the number of Lactococcus lactis, Lactobacillus carvatus, Pediococcus pentaseceous, Lactobacillus plantarum, and totally aerobic and anaerobic bacteria in all treatments. The highest number of bacterial was recorded in the diet containing $80 \%$ soybean meal and $2 \mathrm{~g} / \mathrm{kg}$ enzyme (treatment 9 ). The results of this study indicated that the replacement of fish meal with soybean meal (up to $40 \%$ ) in diet with enzyme at $2 \mathrm{~g} / \mathrm{kg}$ can be suitable as a commercial diet for Beluga Huso huso.

Key words: H. huso, Soybean meal, Growth performance, Fatty acids, Gut lactic acid bacteria 